\title{
Preparation and Characterization of Self-Assembled Thin Film of MPS-Capped ZnS Quantum Dots for Optical Applications
}

\author{
Kenan Koç, ${ }^{1}$ Fatma Z. Tepehan, ${ }^{2}$ and Galip G. Tepehan ${ }^{3}$ \\ ${ }^{1}$ Department of Physics, Yildiz Technical University, Esenler, 34220 Istanbul, Turkey \\ ${ }^{2}$ Department of Physics, Istanbul Technical University, Maslak, 34469 Istanbul, Turkey \\ ${ }^{3}$ Faculty of Arts and Sciences, Kadir Has University, Fatih, 34083 Istanbul, Turkey \\ Correspondence should be addressed to Kenan Koç, kkoc@yildiz.edu.tr \\ Received 25 June 2012; Revised 16 October 2012; Accepted 16 October 2012 \\ Academic Editor: Suprakas Sinha Ray
}

Copyright (C) 2012 Kenan Koç et al. This is an open access article distributed under the Creative Commons Attribution License, which permits unrestricted use, distribution, and reproduction in any medium, provided the original work is properly cited.

\begin{abstract}
For this study, we prepared colloidal ZnS quantum dots using 3-mercaptopropyltrimethoxysilane (MPS) as the capping agent. Colloidal ZnS quantum dots were directly deposited on glass substrates by a spin coating process. Therefore, self-assembled films made of $\mathrm{ZnS}$ quantum dots in a $\mathrm{SiO}_{2}$ network were obtained using only one production step. The films were heat-treated at $100^{\circ}$, $125^{\circ}, 150^{\circ}, 175^{\circ}$ and $200^{\circ} \mathrm{C}$ in an $\mathrm{N}_{2}$ atmosphere. The results showed that the dimension of quantum dots changed from $2.8 \mathrm{~nm}$ to $3.2 \mathrm{~nm}$ by heat treatment. The refractive index, extinction coefficient, thickness, and dielectric coefficient values of the films were calculated. The present study showed that size and the refractive indices of films can be controlled by the heat treatment. Therefore, such films can be a good candidate in optical filter applications.
\end{abstract}

\section{Introduction}

Nanoparticles have been extensively investigated due to their interesting size-dependent, optoelectronic, and physicochemical properties. Semiconductor nanoparticles belonging to II-VI group elements show significant quantum confinement effects [1]. Due to these effects, an exciting area of application of II-VI group nanoparticles is that of photonic band gap materials. Therefore, II-VI group nanoparticles can be used for the manipulation of light propagation and spontaneous emission [2]. Among these, $\mathrm{ZnS}$ nanoparticles have been widely used in optoelectronics such as solar cells, display panels, and optical sensors due to its wide band gap value at the visible wavelength region $[3,4]$. $\mathrm{ZnS}$ nanoparticles and $\mathrm{ZnS}$ thin films can be produced by several methods [2-8]. One of these is the colloidal method, which has the advantages of easy production of semiconductive quantum dots, controlled size distribution, inexpensiveness, and the possibility of producing many quantum dots in a short time period.

One of the capping agents used in colloidal quantum dot production is 3-mercaptopropyltrimethoxysilane (MPS). Addition of MPS in the solvent will serve as a precursor for the growth of silica shell around the particle. Such a shell is chemically inert and optically transparent [2].

The MPS molecule has 2 functional groups. One of these is the thiol $(-\mathrm{SH})$ group, which is able to make covalent bonds with different metals [9]. Therefore, $-\mathrm{SH}$ groups can be used to attach metallic nanostructures to the surface [10, 11]. This makes it a promising candidate for the production of quantum dots because of its ability to combine with the surface of II-VI group nanoparticles [4, 5, 12-14]. The other functional group of MPS is trimethoxysilane. In most applications, MPS molecules are attached to a substrate or film surface due to the Si-O-Si bonds of the trimethoxysilane group [14-17]. Trimethoxysilane is also used to make Si$\mathrm{O}-\mathrm{Si}$ bonds with MPS molecules and therefore to create $\mathrm{SiO}_{2}$ networks. Si-O-Si bonds are created with the help of hydrolysis and the condensation reactions of the solgel method [14-17]. Producing a thin film via the sol-gel method is preferable because of its lower cost and availability in industrial production, as it is independent of the substrate geometry.

Silica is an ideal shell material for $\mathrm{ZnS}$ nanoparticles since its refractive index is significantly lower than the refractive index of $\mathrm{ZnS}$ [18]. Furthermore, $\mathrm{SiO}_{2}$ has a wide band gap 
$(9.1 \mathrm{eV})$ and has an amorphous film structure [19]. For these reasons, some thin films are produced by introducing $\mathrm{ZnS}$ nanoparticles into an $\mathrm{SiO}_{2}$ matrix [18-24]. Such studies usually include two production steps, and the samples are obtained using the following procedures. First, colloidal $\mathrm{ZnS}$ nanoparticles are produced; then the $\mathrm{SiO}_{2}$ coatings on the $\mathrm{ZnS}$ nanoparticle are synthesized by the sol-gel method using tetraethyl orthosilicate (TEOS) as the precursor material. Second, $\mathrm{SiO}_{2}$ sol is produced using TEOS; then the precursor solutions of $\mathrm{ZnS}$ are added in the $\mathrm{SiO}_{2}$ sol [20-24]. On the other hand, in the present study, we prepared colloidal $\mathrm{ZnS}$ quantum dots using MPS as a capping agent. As explained above, MPS in the solvent was also served as a precursor for the growth of $\mathrm{SiO}_{2}$ to incorporate the quantum dots in a silica matrix [25]. Compared with other multistep procedures, in the present method, self-assembled films made of $\mathrm{ZnS}$ quantum dots in $\mathrm{a} \mathrm{SiO}_{2}$ network were obtained using only one production step.

\section{Experiment}

2.1. Production of Quantum Dots and Thin Films. $\mathrm{ZnS}$ nanoparticles were produced using zinc acetate $\left(\mathrm{Zn}\left(\mathrm{CH}_{3} \mathrm{COO}\right)_{2} \cdot 2 \mathrm{H}_{2} \mathrm{O}\right)$ : thioacetamide $\left(\mathrm{CH}_{3} \mathrm{CSNH}_{2}\right)=1$ molar ratio. Zinc acetate and thioacetamide were solved in methanol in two different beakers using zinc acetate: methanol $=0.02$ and thioacetamide: methanol $=0.02$ molar ratios. MPS $\left(\mathrm{HS}\left(\mathrm{CH}_{2}\right)_{3} \mathrm{Si}\left(\mathrm{OCH}_{3}\right)_{3}\right)$, as the surface capping agent, was added to the beaker, including zinc acetate and methanol at MPS: $\mathrm{Zn}=0.3$ molar ratio. Finally, the two solutions in the beakers were mixed in another beaker at $60^{\circ} \mathrm{C}$ in an $\mathrm{N}_{2}$ atmosphere for 10 minutes. The solution with MPS-capped ZnS quantum dots was coated on Corning 2947 glass substrates using the spin coating method at $2000 \mathrm{rpm}$ rotation speed for 10 seconds. The coated films were dried at $60^{\circ} \mathrm{C}$ for 10 minutes. Then they were heattreated at $100,125,150,175$, and $200^{\circ} \mathrm{C}$ in an $\mathrm{N}_{2}$ atmosphere for 15 minutes. Another part of the solution was kept in laboratory conditions for 2 weeks to produce it in a gel form. Then, powdered MPS-capped $\mathrm{ZnS}$ quantum dots were obtained by grinding the gel. The powdered samples are used for the X-ray diffraction (XRD), high resolution transmission electron microscope (HRTEM), and Fourier transform-infrared (FT-IR) measurements.

2.2. Characterization. XRD measurements were performed using a diffractometer (GBC-MMA) operated at $35 \mathrm{kV}$ and $28 \mathrm{~mA}$ using $\mathrm{CuK}_{\alpha}$ radiation. HRTEM images of the MPS capped $\mathrm{ZnS}$ quantum dots in powder form were recorded using a JEOL 2100 HRTEM microscope operated at $200 \mathrm{kV}$. The powdered form of nanoparticles and $\mathrm{KBr}$ were thoroughly mixed, and the mixture was pressed to form a pellet. Then the spectrum was recorded using an FT-IR spectrometer (Perkin Elmer Spectrum One). The optical absorption spectra of the samples were recorded with a UV-visible spectrometer (Agilent 8453). Transmittance of the films was measured at a $30^{\circ}$ angle of incidence in $s$ and p polarizations in the spectral range of $300-1000 \mathrm{~nm}$ using an NKD 7000 (Aquila Instruments, England) spectrophotometer. The

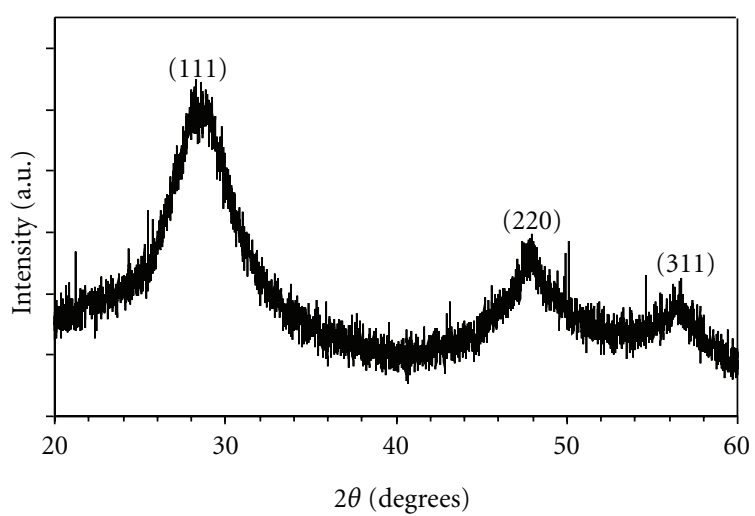

FIGURE 1: XRD patterns of the MPS-capped ZnS quantum dots in powder form.

refractive indices, extinction coefficients, and thickness of the films were evaluated using a modified Levenburg-Marquardt procedure in a Pro-Optix data analysis software package. Transmittance curves between the 300 and $1000 \mathrm{~nm}$ range were fitted to the Drude-Lorentz model. The thickness of the films was determined by a profilometer (Veeco Dektak 150). The surface roughness of the film was characterized by an atomic force microscope (AFM, SPM-9500 J3, Shimadzu).

\section{Results and Discussion}

Figure 1 shows the XRD data for the powder of MPScapped $\mathrm{ZnS}$ quantum dots. The peaks in the graph have $2 \theta$ values of $28.24^{\circ}, 47.72^{\circ}$, and $56.63^{\circ}$ and $d$-spacing values of $0.3157,0.1904$, and $0.1634 \mathrm{~nm}$, respectively. These results correspond to (111), (220), and (311) planes and show a cubic ZnS crystal structure (JCPDS No. 77-2100).

The average particle size can be found from the XRD measurements using the Scherrer equation [26] given by

$$
L=\frac{0.9 \lambda}{\beta \cos \theta}
$$

where $\lambda$ is the wavelength of the $\mathrm{X}$-ray source $(0.154 \mathrm{~nm})$, $\beta$ is the full width at half maximum of the peak at the Bragg angle, and $L$ is the coherence length. Average particle size for spherical particles, $D$, is given by $D=4 L / 3$ [26]. Average particle size of $\mathrm{ZnS}$ quantum dots was found to be $2.73 \mathrm{~nm}$, using the peak corresponding to (111) plane.

The HRTEM picture of MPS-capped ZnS quantum dots is given in Figure 2. The particle size of the quantum dots was calculated from the HRTEM picture and found to be in between 2.5 and $3 \mathrm{~nm}$. This value is in agreement with the particle sizes calculated from XRD measurement.

The FT-IR curve of the powder form of the $\mathrm{ZnS}$ quantum dots is given in Figure 3. The peak at $473 \mathrm{~cm}^{-1}$ can be assigned to Si-O-Si bonding [27]. The peaks at $690 \mathrm{~cm}^{-1}$ and $917 \mathrm{~cm}^{-1}$ belong to the $\mathrm{C}-\mathrm{Si}$ and $\mathrm{Si}-\mathrm{OH}$ bonds, respectively [17]. The most prominent peaks of an MPS molecule in FT-IR curve at $1027 \mathrm{~cm}^{-1}$ and $1115 \mathrm{~cm}^{-1}$ belong to the asymmetric stretching of the Si-O-C and Si-O-Si bonds, 


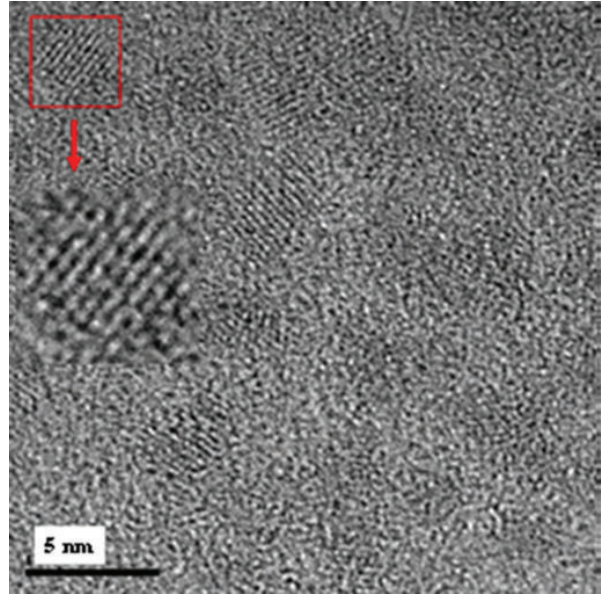

FIgURE 2: HRTEM picture of MPS-capped ZnS quantum dots in powder form.

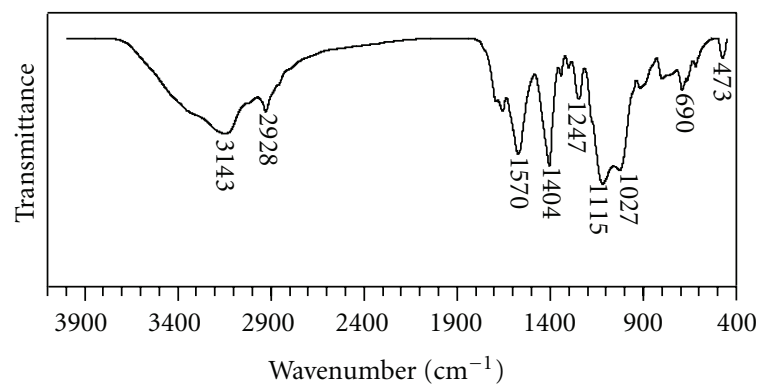

FIGURE 3: FT-IR graph of MPS-capped ZnS quantum dots in powder form.

respectively $[17,28,29]$. The peak at $1247 \mathrm{~cm}^{-1}$ belongs to $\mathrm{Si}-\mathrm{CH}_{2}-\mathrm{S}$ stretching [28]. The peak at $1404 \mathrm{~cm}^{-1}$ is due to the asymmetric deformation of $\mathrm{C}-\mathrm{H}$ in $\mathrm{CH}_{3}$ [30]. The peak at $1570 \mathrm{~cm}^{-1}$ may be attributed to the $\mathrm{S}-\mathrm{S}$ bond [27] . The peak at $1657 \mathrm{~cm}^{-1}$ indicates the presence of $\mathrm{C}=\mathrm{C}$ in the MPS molecules [31]. The peaks at $2928 \mathrm{~cm}^{-1}$ and $3143 \mathrm{~cm}^{-1}$ belong to the $\mathrm{C}-\mathrm{H}$ and $\mathrm{O}-\mathrm{H}$ bonds, respectively $[27,28]$. FT-IR results shows that MPS molecules create an $\mathrm{SiO}_{2}$ network by producing Si-O-Si interbonds. As explained in our previous work [14], during the formation of the thin films, we suppose that quantum dots were attached to the glass surface by $\mathrm{Si}-\mathrm{O}-\mathrm{Si}$ bonds created by the $\mathrm{OH}$ groups of the glass surface and the $\mathrm{Si}-\mathrm{O}$ groups of MPS.

XRD and HRTEM measurements showed that the average radii of the nanoparticles in this study are below the excitonic Bohr radius of bulk $\mathrm{ZnS}(\sim 2.5 \mathrm{~nm})$. It is reasonable to assume a strong confinement for electrons and holes in the $\mathrm{ZnS}$ nanoparticles and assuming nanoparticle in a spherical box model. Absorbances of the films and their second derivative curves in the range between 250 and $350 \mathrm{~nm}$ are shown in Figure 4 . The first exciton peak positions $\left(E_{1 \mathrm{~s} s \mathrm{~s}}\right)$ were calculated from the first minimum of the second derivative of the absorbances data (Figure 4).
TABLE 1: Calculated value of particle size $\left(2 R_{\text {ave }}\right)$ by using the first exciton peak. First exciton peak $\left(E_{1 s 1 s}\right)$ values are extracted from the second derivative of the absorbance spectra.

\begin{tabular}{lcc}
\hline $\begin{array}{l}\text { Heat treatment } \\
\text { temperature }\left({ }^{\circ} \mathrm{C}\right)\end{array}$ & $E_{1 s 1 \mathrm{~s}}(\mathrm{eV})$ & $2 R_{\text {ave }}(\mathrm{nm})$ \\
\hline 100 & 4.75 & 2.84 \\
125 & 4.70 & 2.90 \\
150 & 4.63 & 2.98 \\
175 & 4.54 & 3.10 \\
200 & 4.46 & 3.24 \\
\hline
\end{tabular}

Particle in a spherical box model, the first exciton peak position is given by [32]

$$
\begin{aligned}
E_{1 s 1 \mathrm{~s}}= & E_{g}+\frac{\hbar^{2} \pi^{2}}{2 R^{2}}\left(\frac{1}{m_{e}^{*}}+\frac{1}{m_{h}^{*}}\right)-\frac{1.786 e^{2}}{\varepsilon R} \\
& -0.248 \frac{e^{4}}{2 \varepsilon^{2} \hbar^{2}}\left(\frac{1}{m_{e}^{*}}+\frac{1}{m_{h}^{*}}\right)^{-1},
\end{aligned}
$$

where $E_{g}$ is the band gap energy of the bulk material ( $3.6 \mathrm{eV}$ for $\mathrm{ZnS}$ ), $R$ is the radius of the nanoparticle, $m_{e}^{*}$ and $m_{h}^{*}$ are the effective mass values of electrons and holes, respectively, $\left(m_{e}^{*}=0.34 m_{0}\right.$ and $m_{h}^{*}=0.23 m_{0}$ for $\left.\mathrm{ZnS}\right)$, and $\varepsilon$ is the dielectric constant (8.76 for $\mathrm{ZnS}$ ) [33]. The average particle size of these films is calculated by inserting $E_{1 s 1 s}$ values into (2). Table 1 shows the $E_{1 s 1 s}$ values and the average nanoparticle size of these films. The sizes of the $\mathrm{ZnS}$ quantum dots were grown from approximately 2.8 to $3.2 \mathrm{~nm}$, and the $E_{1 \mathrm{~s} 1 \mathrm{~s}}$ values were shifted from approximately 4.8 to $4.5 \mathrm{eV}$. These results show that the red shift of $E_{1 s 1 s}$ values with increasing heat treatment temperature is due to the increasing nanocrystal radius (quantum size effect). It is most likely that temperature effect causes Ostwald ripening. In that small nanocrystals are dissolved and then redeposited on to the larger nanocrystals, resulting in a larger particle size [34].

Figure 5 shows the optical transmittance of the films in $s$ and p polarizations at the spectral range of $300-1000 \mathrm{~nm}$. Table 2 shows the optical transmittance and their respective optical constants of the films in $\mathrm{s}$ and $\mathrm{p}$ polarizations at $550 \mathrm{~nm}$ for the films heat treated at 100,150 , and $200^{\circ} \mathrm{C}$. Transmittance is higher for $\mathrm{p}$ polarization, and the results show that all of the films are transparent.

Figure 6 shows the wavelength dependence of the refractive index, and the extinction coefficient of the films is between 300 and $1000 \mathrm{~nm}$. The result showed that the refractive index decreases and the extinction coefficient increases as the heat treatment temperature rises. As expected, the refractive index values of the films were found to be between the refractive index of the bulk $\mathrm{ZnS}$ (2.36) [35] and that of the MPS in film form (1.45) [17]. This behaviour is similar to the results on nanocrystalline $\mathrm{ZnS}-\mathrm{SiO}_{2}$ composite films which were previously reported by Thielsch et al. [19]. They said that "The refractive index of the composite increases with increasing concentration of $\mathrm{ZnS}$ from about 1.48 (the value of a pure $\mathrm{SiO}_{2}$ film) to 2.30 for a pure $\mathrm{ZnS}$ film." 


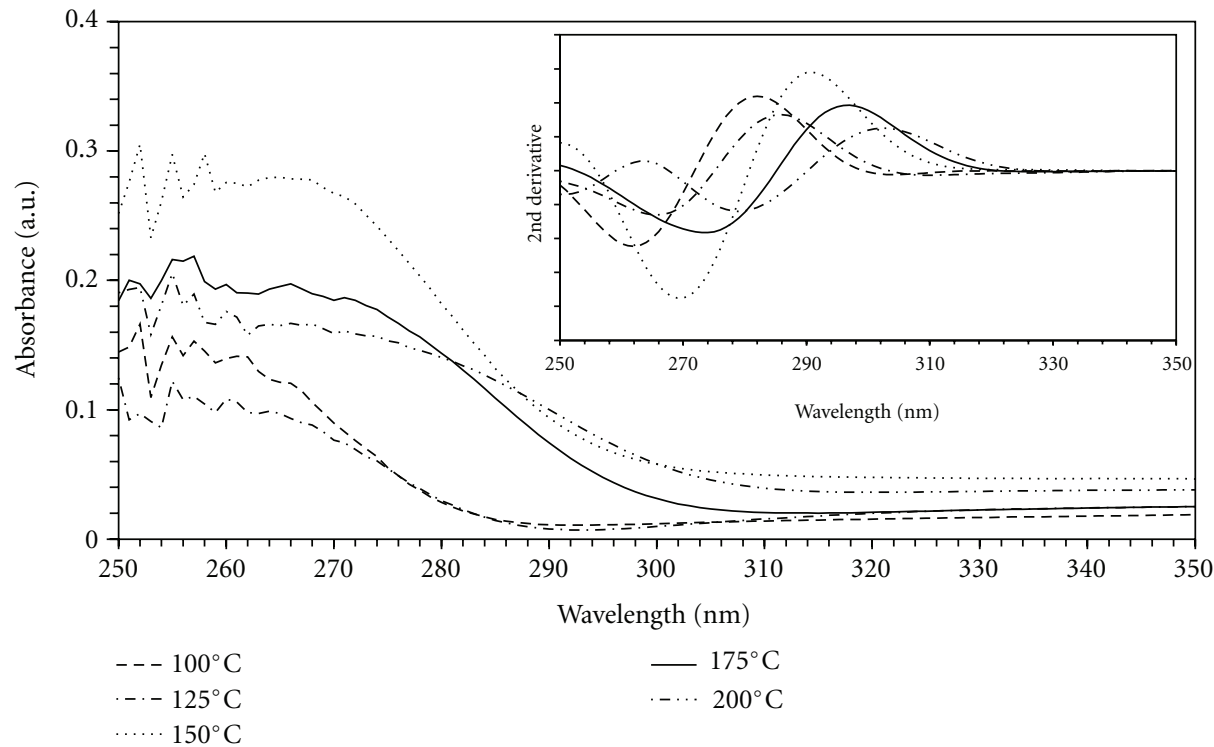

FIGURE 4: Absorbance graph of thin films forms of MPS-capped ZnS quantum dots heat-treated at different temperatures and second derivatives of absorbance spectra for the films.

TABLE 2: Thickness and optical parameters (at $\lambda=550 \mathrm{~nm}$ ) for self-assembled thin films forms of MPS-capped ZnS quantum dots.

\begin{tabular}{lcccccccc}
\hline $\begin{array}{l}\text { Heat treatment } \\
\text { temperature }\left({ }^{\circ} \mathrm{C}\right)\end{array}$ & $\begin{array}{c}d(\mathrm{~nm})(\text { from } \\
\text { profilometer }\end{array}$ & $\begin{array}{c}d(\mathrm{~nm}) \\
(\text { from NKD) }\end{array}$ & $\begin{array}{c}\text { Transmittance } \\
\text { in p polarization }\end{array}$ & $\begin{array}{c}\text { Transmittance } \\
\text { in s polarization }\end{array}$ & $n$ & $k$ & $\mathcal{E}_{1}$ & $\mathcal{E}_{2}$ \\
\hline 100 & 100 & 97 & 0.90 & 0.81 & 1.82 & 0.007 & 3.30 & 0.024 \\
150 & 84 & 79 & 0.89 & 0.81 & 1.76 & 0.014 & 3.09 & 0.048 \\
200 & 74 & 72 & 0.88 & 0.80 & 1.68 & 0.023 & 2.80 & 0.078 \\
\hline
\end{tabular}

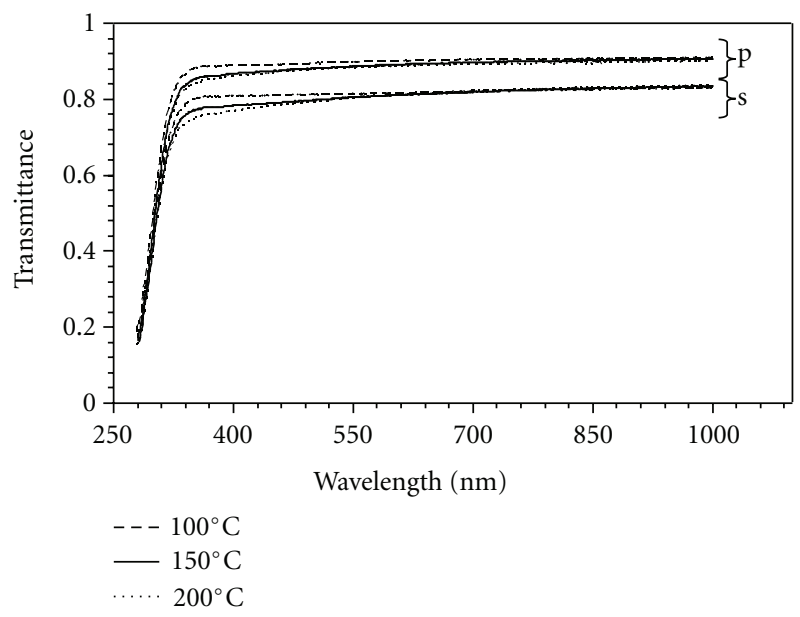

FIGURE 5: Transmittances of thin films forms of MPS-capped ZnS quantum dots in $\mathrm{s}$ and $\mathrm{p}$ polarizations.

ProOptix optical data analysis software was used to calculate the thickness, and the results were checked with a profilometer (Table 2 ). The result showed that film thickness and refractive index decreased as the heat treatment temperature increased. Similar behaviour was previously reported by Mohamed et al. [35] for the relationship between



FIGURE 6: Variation of refractive index and extinction coefficient with wavelength for thin films forms of MPS-capped $\mathrm{ZnS}$ quantum dots heat-treated at different temperatures.

the refractive index and thickness of nanostructure $\mathrm{ZnS}$ films. They showed that packing density and therefore the refractive index of $\mathrm{ZnS}$ films values decrease with increasing film thickness. 


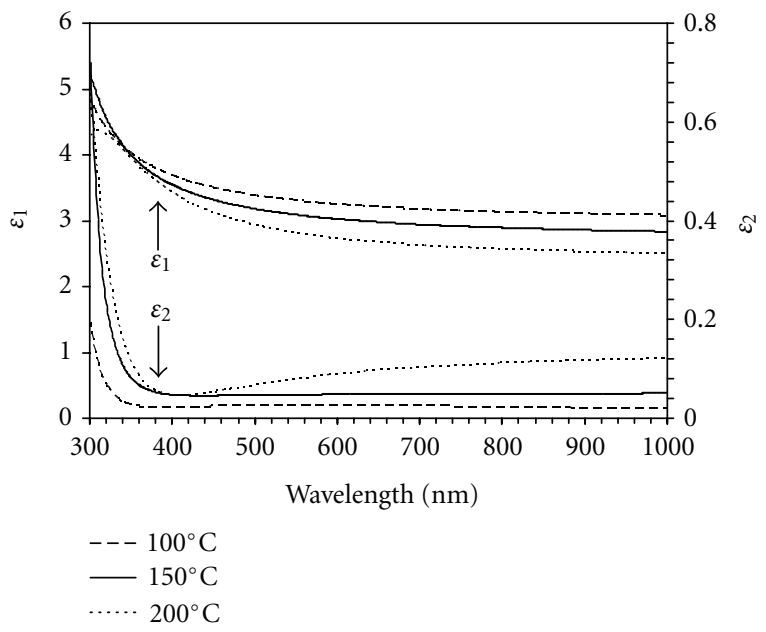

FIGURE 7: Variation of real $\left(\varepsilon_{1}\right)$ and imaginary parts $\left(\varepsilon_{2}\right)$ of the dielectric function with wavelength for thin films forms of MPS-capped ZnS quantum dots heat-treated at different temperatures.
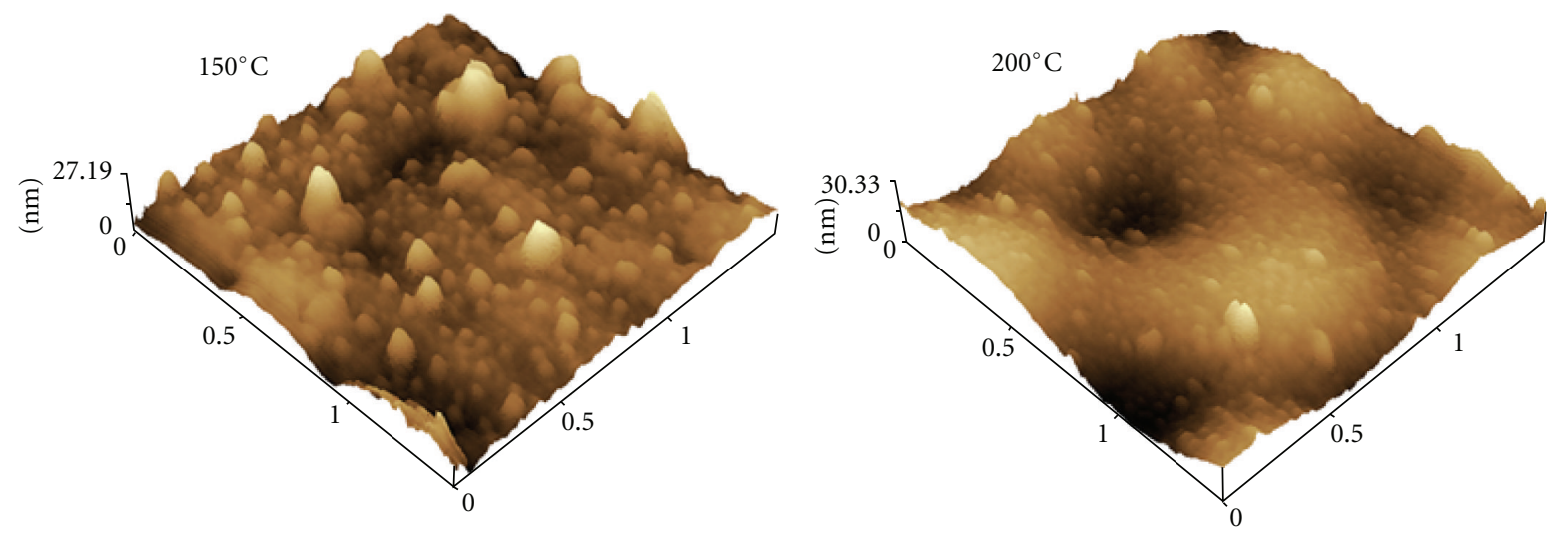

FIGURE 8: AFM images (scan area: $1.50 \mu \mathrm{m} \times 1.50 \mu \mathrm{m}$ ) of thin films forms of MPS-capped ZnS quantum dots heat-treated at $150^{\circ} \mathrm{C}$ and $200^{\circ} \mathrm{C}$.

The complex dielectric constant is given by $\widetilde{\varepsilon}=\varepsilon_{1}+i \varepsilon_{2}$, where $\varepsilon_{1}$ and $\varepsilon_{2}$ are real, and the imaginary parts of the dielectric function can be calculated by $\varepsilon_{1}=n^{2}-k^{2}$ and $\varepsilon_{2}=2 n k$, respectively. Calculated real and imaginary parts of the dielectric function are given in Figure 7. The real and imaginary parts of the dielectric function of the films at $550 \mathrm{~nm}$ for the films heat treated at 100,150 , and $200^{\circ} \mathrm{C}$ are given in Table 2. The real and imaginary parts of the dielectric function show the characteristics of the refractive index and extinction coefficient, respectively.

The AFM images of the ZnS thin films deposited on Corning glass substrates and heat-treated at $150^{\circ} \mathrm{C}$ and $200^{\circ} \mathrm{C}$ are shown in Figure 8. The root mean square (Rms) surface roughness of the films is 3.50 and $4.23 \mathrm{~nm}$, respectively. The image shows that the root mean square surface roughness increases with the increase of annealing temperature. This will increase the pores and decrease the packing density in films which results in the decrease of refractive indices and increase of extinction coefficient of the films [36].

\section{Conclusion}

The present study aimed at preparation and characterization of self-assembled MPS-capped ZnS thin film of quantum dots for optical applications. Quantum dots were selfassembled directly on a glass substrate using spin coating method without introducing any matrix. Therefore, selfassembled films made of $\mathrm{ZnS}$ quantum dots in an $\mathrm{SiO}_{2}$ network were obtained using only one production step. This study showed that size and the refractive indices of MPS capsulated films can be controlled by heat treatment. Therefore, such type of thin films can be a good candidate in optical filter applications [37] where the main difficulty is to have a controlable refractive index and thickness.

\section{Acknowledgments}

The authors would like to thank Dr. Bahadir Keskin for the FT-IR measurement. This work is supported by the Research Fund of Istanbul Technical University. 


\section{References}

[1] J. Planelles-Aragó, E. Cordoncillo, R. A. S. Ferreira, L. D. Carlos, and P. Escribano, "Synthesis, characterization and optical studies on lanthanide-doped CdS quantum dots: new insights on CdS $\rightarrow$ lanthanide energy transfer mechanisms," Journal of Materials Chemistry, vol. 21, no. 4, pp. 1162-1170, 2011.

[2] K. P. Velikov and A. van Blaaderen, "Synthesis and characterization of monodisperse core-shell colloidal spheres of zinc sulfide and silica," Langmuir, vol. 17, no. 16, pp. 4779-4786, 2001.

[3] S. H. Mohamed, "Photocatalytic, optical and electrical properties of copper-doped zinc sulfide thin films," Journal of Physics D, vol. 43, no. 3, Article ID 035406, 8 pages, 2010.

[4] H. Li, W. Y. Shih, and W.-H. Shih, "Stable aqueous ZnS quantum dots obtained using (3-mercaptopropyl) trimethoxysilane as a capping molecule," Nanotechnology, vol. 18, no. 49, Article ID 495605, 7 pages, 2007.

[5] J. Chung, S. Lee, and D. U. J. Jang, "ZnS nanoparticle treatment to enhance its luminescence, shape, and stability," Molecular Crystals and Liquid Crystals, vol. 377, no. 1, pp. 85-88, 2002.

[6] N. Hebalkar, A. Lobo, S. R. Sainkar et al., "Properties of zinc sulphide nanoparticles stabilized in silica," Journal of Materials Science, vol. 36, no. 18, pp. 4377-4384, 2001.

[7] N. Fathy and M. Ichimura, "Photoelectrical properties of $\mathrm{ZnS}$ thin films deposited from aqueous solution using pulsed electrochemical deposition," Solar Energy Materials and Solar Cells, vol. 87, no. 1-4, pp. 747-756, 2005.

[8] T. Zhai, Z. Gu, Y. Ma, W. Yang, L. Zhao, and J. Yao, "Synthesis of ordered ZnS nanotubes by MOCVD-template method," Materials Chemistry and Physics, vol. 100, no. 2-3, pp. 281284, 2006.

[9] R. Tremont, H. D. Jesús-Cardona, J. García-Orozco, R. J. Castro, and C. R. Cabrera, "3-Mercaptopropyltrimethoxysilane as a Cu corrosion inhibitor in $\mathrm{KCl}$ solution," Journal of Applied Electrochemistry, vol. 30, no. 6, pp. 737-743, 2000.

[10] K. C. Grabar, P. C. Smith, M. D. Musick et al., "Kinetic control of interparticle spacing in Au colloid-based surfaces: rational nanometer-scale architecture," Journal of the American Chemical Society, vol. 118, no. 5, pp. 1148-1153, 1996.

[11] M. Brust, D. Bethell, C. J. Kiely, and D. J. Schiffrin, "Selfassembled gold nanoparticle thin films with nonmetallic optical and electronic properties," Langmuir, vol. 14, no. 19, pp. 5425-5429, 1998.

[12] Q. Wang, N. Iancu, and D. K. Seo, "Preparation of large transparent silica monoliths with embedded photoluminescent CdSe@ZnS core/shell quantum dots," Chemistry of Materials, vol. 17, no. 19, pp. 4762-4764, 2005.

[13] M. Guglielmi, A. Martucci, E. Menegazzo et al., "Control of semiconductor particle size in sol-gel thin films," Journal of Sol-Gel Science and Technology, vol. 8, no. 1-3, pp. 1017-1021, 1997.

[14] K. Koç, F. Z. Tepehan, and G. G. Tepehan, "Characterization of MPS capped CdS quantum dots and formation of selfassembled quantum dots thin films on a glassy substrate," Chalcogenide Letters, vol. 8, no. 4, pp. 239-247, 2011.

[15] J. Singh and J. E. Whitten, "Adsorption of 3-mercaptopropyltrimethoxysilane on silicon oxide surfaces and adsorbate interaction with thermally deposited gold," Journal of Physical Chemistry C, vol. 112, no. 48, pp. 19088-19096, 2008.

[16] A. Scott and J. E. Gray-Munro, "The surface chemistry of 3-mercaptopropyltrimethoxysilane films deposited on magnesium alloy AZ91," Thin Solid Films, vol. 517, no. 24, pp. 6809-6816, 2009.

[17] W. R. Thompson, M. Cai, M. Ho, and J. E. Pemberton, "Hydrolysis and condensation of self-assembled monolayers of (3-mercaptopropyl)trimethoxysilane on $\mathrm{Ag}$ and $\mathrm{Au}$ surfaces," Langmuir, vol. 13, no. 8, pp. 2291-2302, 1997.

[18] B. Steitz, Y. Axmann, H. Hofmann, and A. Petri-Fink, "Optical properties of annealed $\mathrm{Mn}^{2+}$-doped $\mathrm{ZnS}$ nanoparticles," Journal of Luminescence, vol. 128, no. 1, pp. 92-98, 2008.

[19] R. Thielsch, T. Böhme, and H. Böttcher, "Optical and structural properties of nanocrystalline $\mathrm{ZnS}-\mathrm{SiO}_{2}$ composite films," Physica Status Solidi (A), vol. 155, no. 1, pp. 157-170, 1996.

[20] B. Bhattacharjee, D. Ganguli, S. Chaudhuri, and A. K. Pal, "Synthesis and optical characterization of sol-gel derived zinc sulphide nanoparticles confined in amorphous silica thin films," Materials Chemistry and Physics, vol. 78, no. 2, pp. 372379, 2003.

[21] C. L. Wang, L. Gou, J. M. Zaleski, and D. L. Friesel, "ZnS quantum dot based nanocomposite scintillators for thermal neutron detection," Nuclear Instruments and Methods in Physics Research A, vol. 622, no. 1, pp. 186-190, 2010.

[22] J. Mu, D. Gu, and Z. Xu, "Synthesis and stabilization of ZnS nanoparticles embedded in silica nanospheres," Applied Physics A, vol. 80, no. 7, pp. 1425-1429, 2005.

[23] P. Yang, M. K. Lü, C. F. Song et al., "Strong visible-light emission of ZnS nanocrystals embedded in sol-gel silica xerogel," Materials Science and Engineering B, vol. 97, no. 2, pp. 149153, 2003.

[24] B. Bhattacharjee, D. Ganguli, K. Iakoubovskii, A. Stesmans, and S. Chaudhuri, "Synthesis and characterization of solgel derived $\mathrm{ZnS}$ : $\mathrm{Mn}^{2+}$ nanocrystallites embedded in a silica matrix," Bulletin of Materials Science, vol. 25, no. 3, pp. 175$180,2002$.

[25] S. F. Wuister and A. Meijerink, "Synthesis and luminescence of CdS quantum dots capped with a silica precursor," Journal of Luminescence, vol. 105, no. 1, pp. 35-43, 2003.

[26] J. Nanda, S. Sapra, D. D. Sarma, N. Chandrasekharan, and G. Hodes, "Size-selected zinc sulfide nanocrystallites: synthesis, structure, and optical studies," Chemistry of Materials, vol. 12, no. 4, pp. 1018-1024, 2000.

[27] N. Hebalkar, S. Kharrazi, A. Ethiraj, J. Urban, R. Fink, and S. K. Kulkarni, "Structural and optical investigations of $\mathrm{SiO}_{2}-\mathrm{CdS}$ core-shell particles," Journal of Colloid and Interface Science, vol. 278, no. 1, pp. 107-114, 2004.

[28] B. Stuart, Modern Infrared Spectroscopy, John Wiley \& Sons, New York, NY, USA, 1996.

[29] J. Habsuda, G. P. Simon, Y. B. Cheng, D. G. Hewitt, D. A. Lewis, and H. Toh, "Organic-inorganic hybrids derived from 2hydroxyethylmethacrylate and (3-methacryloyloxypropyl)trimethoxysilane," Polymer, vol. 43, no. 15, pp. 4123-4136, 2002.

[30] A. G. Hardie, J. J. Dynes, L. M. Kozak, and P. M. Huang, "Influence of polyphenols on the integrated polyphenolmaillard reaction humifýcation pathway as catalyzed by birnessite," Annals of Environmental Science, vol. 1, pp. 91-110, 2007.

[31] E. Tang, H. Liu, L. Sun, E. Zheng, and G. Cheng, "Fabrication of zinc oxide/poly(styrene) grafted nanocomposite latex and its dispersion," European Polymer Journal, vol. 43, no. 10, pp. 4210-4218, 2007.

[32] Y. Kayanuma, "Quantum-size effects of interacting electrons and holes in semiconductor microcrystals with spherical shape," Physical Review B, vol. 38, no. 14, pp. 9797-9805, 1988.

[33] H. Chihara, N. Nakamura, K. H. Hellwege, and A. M. Hellwege, Landolt-Börnstein: Numerical Data and Functional 
Relationships in Science and Technology, vol. 22, Springer, Berlin, Germany, 1987.

[34] C. N. R. Rao, A. Müller, and A. K. Cheetham, Eds., Nanomaterials Chemistry: Recent Developments and New Directions, Wiley-VCH, Weinheim, Germany, 2007.

[35] S. H. Mohamed, M. El-Hagary, and M. Emam-Ismail, "Thickness and annealing effects on the optoelectronic properties of ZnS films," Journal of Physics D, vol. 43, no. 7, Article ID 075401, 7 pages, 2010.

[36] X. Wu, F. Lai, Y. Lin, Z. Huang, and R. Chen, "Effects of substrate temperature and annealing on the structure and optical properties of ZnS film," in 3rd International Symposium on Advanced Optical Manufacturing and Testing Technologies: Advanced Optical Manufacturing Technologies, vol. 6722 of Proceedings of SPIE, pp. 67222L-1-67222L-6, July 2007.

[37] K. Koc, F. Z. Tepehan, and G. G. Tepehan, "Antireflecting coating from $\mathrm{Ta}_{2} \mathrm{O}_{5}$ and $\mathrm{SiO}_{2}$ multilayer films," Journal of Materials Science, vol. 40, no. 6, pp. 1363-1366, 2005. 



The Scientific World Journal

Submit your manuscripts at

http://www.hindawi.com

\section{World Journal}



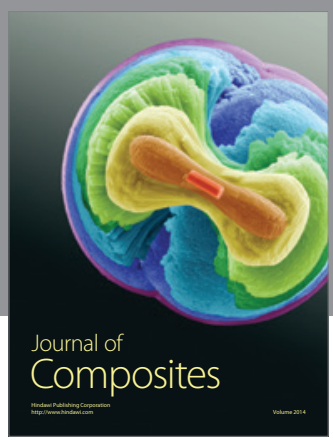
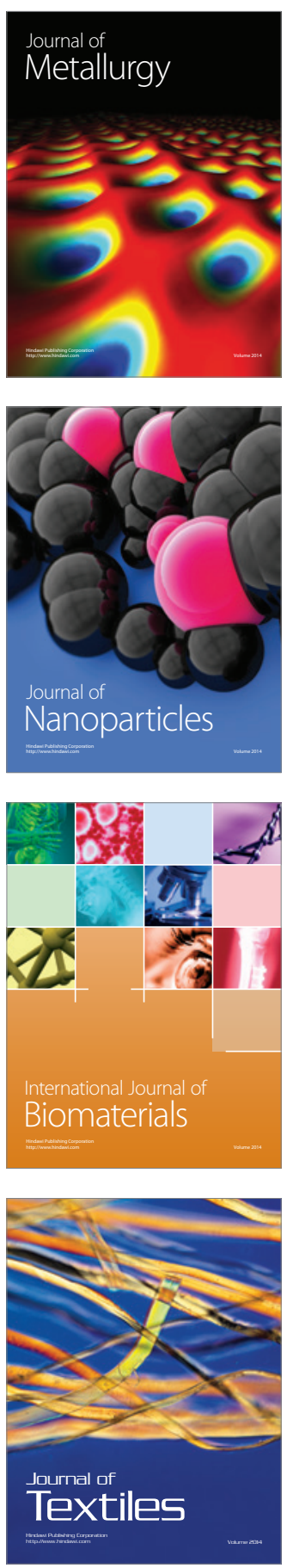